\title{
Monthly Determination of Alginate, M/G Ratio, Mannitol, and Minerals in Cultivated Laminaria japonica
}

\author{
Masura Honya, ${ }^{* 1}$ Tomihisa Kinoshita, ${ }^{* 1}$ Masahiro Ishikawa, ${ }^{* 2}$ \\ Hiroe Mori, ${ }^{* 3}$ and Kazutosi Nisizawa*4
}

(Received June, 18 1992)

\begin{abstract}
In Laminaria japonica cultivated at Date Bay, Hokkaido, we investigated the monthly variation in alginate content and its $M / G$ ratio together with the variation in mannitol and some minerals such as calcium, magnesium, iron, and phosphorous. The following result was obtained. The relative content of the MG block of alginate varied only slightly from March to October in an almost similar pattern to the total alginate content. In contrast, the content of the $\mathrm{M}$ block increased with the growth of kelp toward summer, while that of the $G$ block showed an inverse pattern. The global pat tern of variation in the content of mannitol resembled that of the M block; it increased conspicuously in summer, but decreased gradually toward the end of autumn.

The contents of inorganic elements varied with characteristic patterns, except for calcium which seemed to increase in concert with the increase of the $M$ block toward autumn.
\end{abstract}

Determination of the $\mathrm{M} / \mathrm{G}$ ratio and block proportion of alginate ( $M$ and $G$ refer to $D-$ mannuronic acid and L-guluronic acid residues, respectively) is important since the physical properties of alginate products depend mainly on this $M / G$ ratio which commonly influences the evaluation of the products.

No data are presently available on the $\mathrm{M} / \mathrm{G}$ ratio of alginate of Laminaria japonica in different seasons, and thus it is not known what season the content of $\mathrm{M}$ or $\mathrm{G}$ becomes highest during growth.

Thus, we determined the content of alginate and the $M / G$ ratio in the kelp on a monthly basis.

We also analyzed the content of mannitol in the same blade, because sugar alcohol has been found by ${ }^{14} \mathrm{C}$-incorporation to be a direct photosynthetic product in brown algae' ${ }^{1)}$ and may be the initial precursor of alginate at the $\mathrm{C}_{8}$-monosaccharide level.2) The G block content of some European species of Laminalia is affected largely by the concentration of phosphate in the medium. ${ }^{3-4}$ It may be expected that di- or trivalent metals including calcium accumulate in proportion to alginate content. They have been considered to combine with the acidic polysaccharide each at a different affinity.s) Thus, we investigated the variation in the content of selected metals such as calcium, magnesium, and iron in addition to phosphorous during kelp growth.

\section{Materials and Methods}

\section{Kelp Material}

Zoospores were obtained from matured $L$. japonica collected at Date Bay, Hokkaido, Japan. In November 1985, algal blades reared in culture aparatus in a room were cultivated in the same bay according to Hasegawa's method. ${ }^{\text {() }}$

Kelp was harvested around the middle of each month from March to October, 1986, in such a way that several $10 \mathrm{~m}$-long culture ropes holding kelp were drawn into a boat and the average weitht of individual kelp specimens was estimated on the basis of their total number and weight. Three kelp blades whose weight was close to the average were selected. After washing with filtered seawater, the kelp blades were quickly transported

*1 Research Institute, Ishikawajima-Harima Heavy Industries Co., Ltd., Toyosu, Koto, Tokyo 135-91, Japan (本谷益良, 木下富久: 石川島播磨重工業株式会社，技衔研究所).

*2 Kimitsu Chemical Industries Co. Ltd., Ohori, Futtsu, Chiba 299-12, Japan (石河正裕: 君津化学工策株式 会社).

*3 Tokyo Kasei Gakuin College, Aihara, Machida, Tokyo 194-02, Japan（森 宏枝：椟京家政学院大学家 政学部).

*4 Dept. of Fisheries, College of Agriculture and Veterinary Medicine, Nihon University, Shimouma, Setagaya, Tokyo 154, Japan (西澤一俊: 日本大学農獸医学部). 
to the laboratory in Tokyo by airplane under cooled conditions. The samples were dried at $60^{\circ} \mathrm{C}$ under reduced pressure, and powdered for analysis. For measurement of alginate content and $M / G$ ratio, 10 kelp blades were used after being dried in the same way and crushed into approximately $5 \mathrm{~mm}$ square pieces.

\section{Determination of Ash and Minerals}

Total ash was determined by incineration at $600^{\circ} \mathrm{C}$. Atomic absorption spectrometry was conducted for analysis of $\mathrm{Ca}, \mathrm{Mg}$, and Fe. Phosphorous was determined by molybdenum-blue color reaction by the Fiske-Subbarow method. ${ }^{72}$

\section{Determination of Mannitol}

One gram of kelp powder was mixed with 20 $\mathrm{m} l$ of distilled water for extraction of mannitol and an appropriate amount of inositol was added as the internal standard. The extraction was continued overnight at room temperature, further $20 \mathrm{~m} l$ of water were added and the mixture was homogenized. The supernatant obtained by centrifugation was evaporated to dryness under reduced pressure. One part was subjected to acetylation and the acetylated mannitol was measured by gas liquid chromatography (column; Diasolid ZP, $1 \mathrm{~m} \times 3 \mathrm{~mm}$, Shimadzu).

\section{Determination of Alginate}

After pieces of dried kelp blades had become swollen with distilled water, they were washed with 20 vol. of $0.5 \%$ sulfuric acid solution for $2 \mathrm{~h}$, followed by the addition of 15 vol. of a mixture of $2 \%$ sodium carbonate and $0.1 \%$ sodium hydroxide. Alginate extraction was conducted at $40^{\circ} \mathrm{C}$ overnight with mechanical stirring. The extract was diluted with $200 \mathrm{vol}$. of distilled water and filtered through a filter paper, Toyo No. 2. An aliquot of the neutralized filtrate was used for analysis of total sugar content (A) by the phenolsulfuric acid method. ${ }^{8)}$

Another aliquot of the filtrate was poured into 0.1 vol. of $10 \%$ calcium chloride solution under stirring to obtain a calcium alginate gel. After centrifugation at $3,000 \times \mathrm{g}$ for $20 \mathrm{~min}$, total sugar content (B) in the supernatant was determined quantitatively by the above method. Alginate content in the sample blades was estimated from (A)-(B).

\section{Standard Alginate Preparation}

An alkaline alginate solution prepared from the kelp sample was neutralized and ethanol was added to a $50-60 \%$ final concentration. The sodium alginate precipitate thus formed was purified twice more by repeating dissolution in water and precipitation with ethanol. The last sodium alginate precipitate was dehydrated by treatment with ethanol and acetone and served as the standard alginate for obtaining a calibration curve.

\section{Determination of $M / G$ Ratio}

A neutralized alginate extract from kelp blades was hydrolyzed with a dilute hydrochloric acid solution and fractionated into $M$ (practically $M$ only), $G$ (practically $G$ only) and $M G$ ( $M$ and $G$ mixed) fractions according to the method of Haug et al. ${ }^{8)}$ Each uronic acid residue of these three kinds of uronide blocks was determined by the phenol-sulfuric acid method using standard calibration curves made from standard $M$ and $G$ blocks. On the basis of the values obtained, total amounts of $M$ and $G$ in the starting alginate were calculated.

\section{Results and Discussion}

The monthly variation in seawater temperature in the cultivation ground showed a typical pattern in northern Japan, the maximum being in August, as shown in Fig. 1. The wet weight of kelp blands increased rapidly from June toward midsummer, and then decreased remarkably during autumn (Fig. 1).

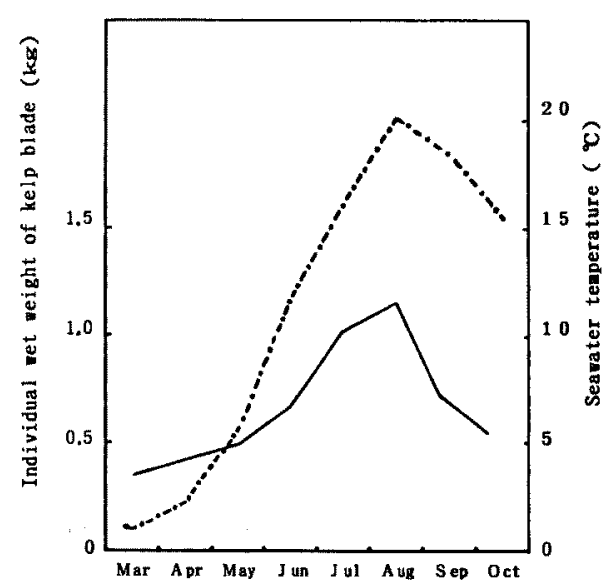

Fig. 1. Monthly variation in seawater temperature and average wet weight of individual blades of Laminaria japonica.

$-\cdot-$, Seawater temperature; - , wet weight of kelp blade. 


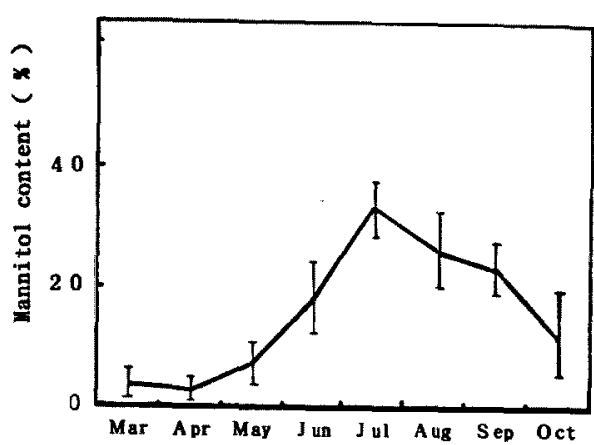

Fig. 2. Monthly variation in mannitol content of kelp blades (\%, on a dry matter basis).

-, Mannitol, -i- standard deviation $(n=10)$.

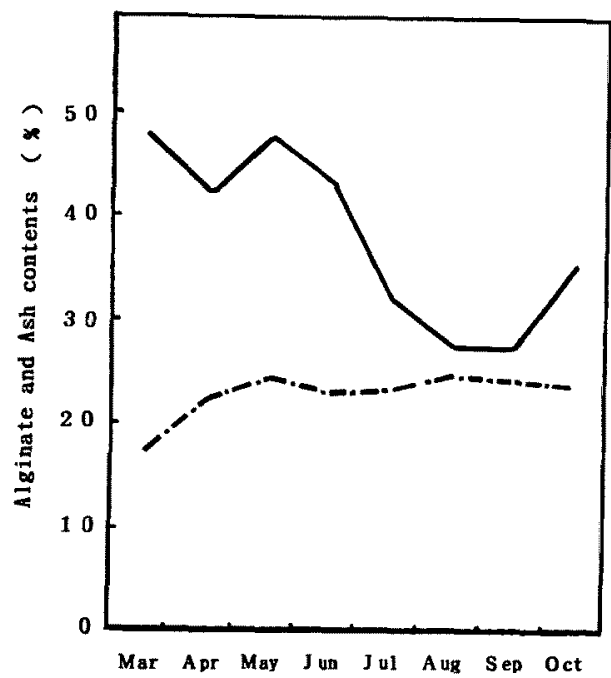

Fig. 3. Monthly variation in alginate, and ash content of kelp blades ( $\%$, on a dry matter basis). -.-, Alginate; - , ash.

Mannitol content varied with the season (Fig. 2). It was lower during spring, at around 5\% of the dry weight, but increased in summer up to more than $30 \%$ of the dry weight when the growth of kelp was maximum.

A conspicuous enhancement of mannitol in summer has been observed by other researchers though they have not measured its content after attaining the maximum. ${ }^{10-18}$ ) This study showed, however, that the content of mannitol decreases rapidly toward early autumn. The decrease in mannitol may suggest that it will be used for sporangium formation in the kelp, ${ }^{14}$ ) since this sugar alcohol is a direct photosynthetic product. ${ }^{2,2\}}$

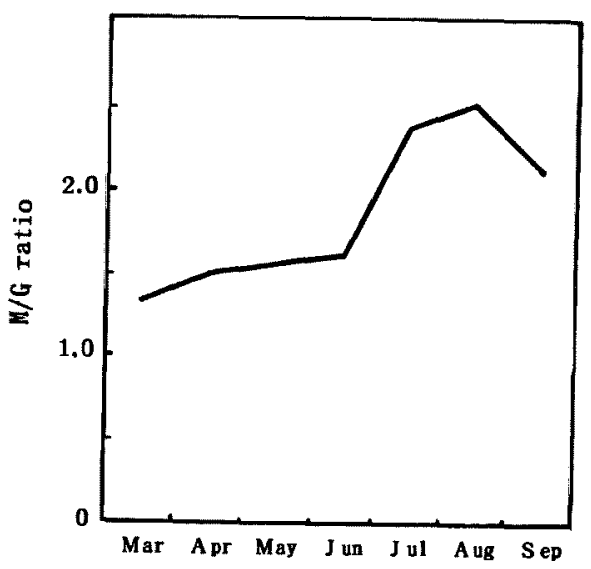

Fig. 4. Monthly variation in $M / G$ ratio of alginate.

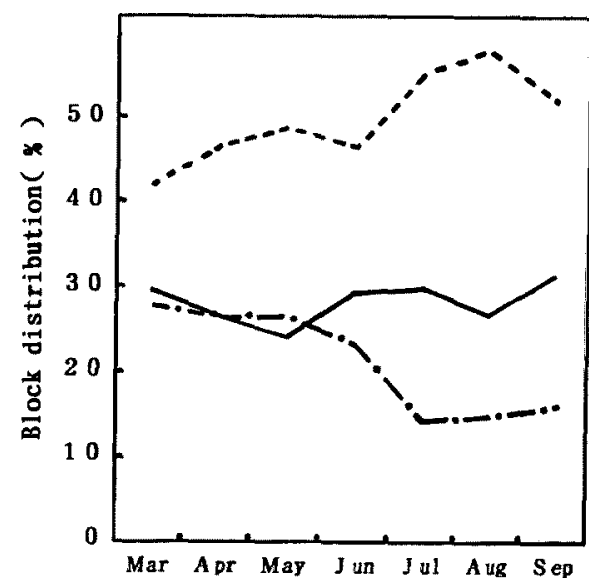

Fig. 5. Monthly variation in the distribution patterns of uronide blocks of alginate $(\%$, on a dry matter basis).

-, MG block; ---, M block;----, G block.

The alginate content of kelp blades showed no remarkable monthly change except from March to May, with a gradual increase from 17 to $25 \%$ (Fig. 3).

Total ash content varied markedly in contrast to alginate content. The higher content in spring decreased toward summer, but began to increase again at the beginning of autumn (Fig. 3).

The $M / G$ ratio began to rise suddenly from the beginning to the end of summer, by a factor of 2.5. The ratio showed a steep decrease toward autumn with the start of sporangium formation (Fig. 4). The $M$ block showed a pattern of 

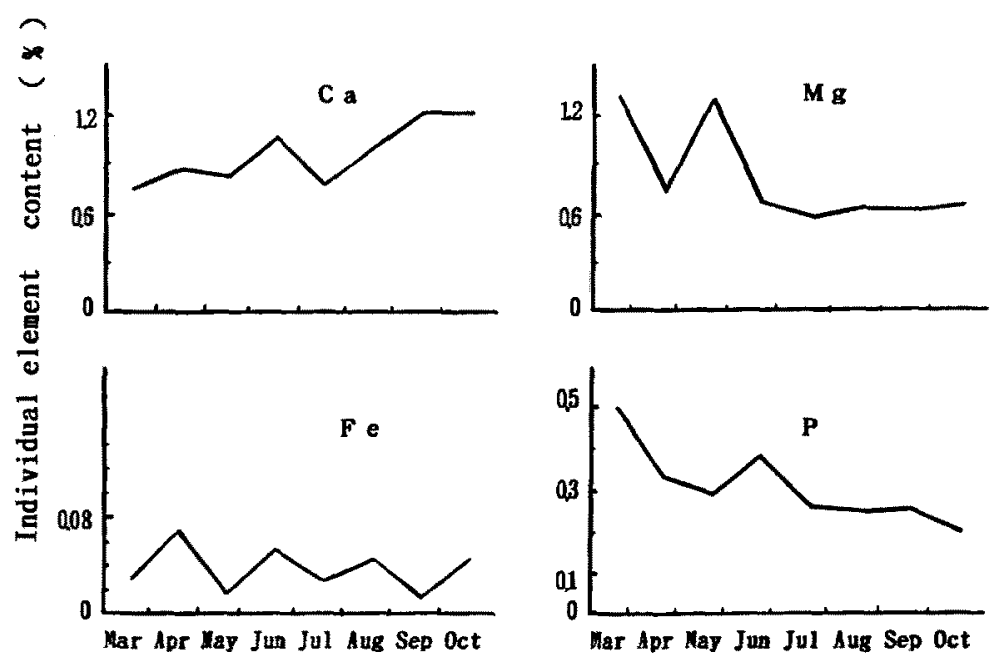

Fig. 6. Monthly variation in the content of some inorganic elements in kelp blades $(\%$, on a dry matter basis).

increase with kelp growth while the $G$ block showed the opposite. The distribution pattern of the MG block did not markedly change throughout March to October (Fig. 5).

The highly mucous surface of the kelp blade in summer may thus possibly be due to water soluble alginate rich in the $M$ block but poor in the $\mathrm{G}$ block. This property should serve to sustain large kelp blades in a physically flexible condition. The smaller amount of total alginate during the spring may be due to a lower production of alginate than in later growth stages, since the amounts $M, G$, and $M G$ blocks are essentially constant regardless of kelp growth during the spring.

Figure 6 shows the monthly variation in the contents of several inorganic elements. The contents of all elements analyzed in this work varied more or less monthly each with a characteristic pattern except for iron which remained almost contstant from March to Autumn, Calcium content increased toward autumn in accordance with the increasing pattern of the $M$ block shown in Fig. 5 .

It is well known that the $G$ block combines readily with calcium to form a stiff gel. The calcium content, therefore, might be assumed to be parallel to the $\mathrm{G}$ block content. However, it was actually found in the present work that the content of $G$ block began to decrease from around the beginning of summer while the calcium content gradually increased. This discrepancy may be explained by an assumption that most calcium increases in the kelp blades must be combined with the $M$ block increases in alginate molecules. In fact, a water soluble $M$-rich alginate has been shown to form a soft gel by the addition of calcium salt (unpublished data).

\section{Acknowledgments}

The authors are grateful to Dr. T. Nakada, Director of the Research Institute of IHI Co., Ltd., for his encouragement throughout this work. Thanks are also due to Date City Office, Hokkaido, for its assistance in algal cultivation.

\section{References}

1) T. Yamaguchi, Y. Ikawa, and K. Nisizawa: Incorporation of radioactive carbon from $\mathrm{H}^{14} \mathrm{CO}_{3}$ - into sugar constituents by the brown alga, Eisenja bicyclis, during photosynthesis and its fate in the dark. Plant and Cell Physiol., 7, 217-229 (1966).

2) T. Ikawa, T. Watanabe, and K. Nisizawa: Enzymes involved in the last steps of the biosynthesis of mannitol in brown algae. Plant and Cell Physiol., 13, $1017-1029$ (1972).

3) M. Indergaards and G. Skjak-Braek: Characteristics of alginate from Laminaria digitata cultivated in a high phosphate environment. Hydrobiologia, 151/152, $541-549$ (1987).

4) A. Jensen: Studies on the infuence of nutrients on the composition and structure of alginate in Laminaria staccharina (L.) Lamour. (Laminariales, Pheacophyceae). Botanica Marina, 33, 277-288 (1990).

5) A. Haug and O. Smidsrod: The effect of divalent metals on the properties of alginate solution. Acta Chem. Scand., 19, 341-351 (1965).

6) Y. Hasegawa: Progress of Laminaria culture in Japan. J. Fish. Res. Boad Canada, 33, 1002-1006 (1976).

7) Pharmaceutical Soc. IPN: Standard methods of analysis 
for hygienic chemists, Kinbara Shuppan, Tokyo Osaka Kyoto, 1980, pp. 77-78 (in Japanese).

8) M. Dubois, K. A. Gillus, J. K. Hamilton, P. A. Rebers, and F. Smith: Colorimetric method for sugars and related substance. Anal. Chem., 28, 350-356 (1956).

9) A. Haug, B. Larsen, and O. Smidsr $\phi$ d: Uronic acid sequence in alginate from different sources. Carbohyd. Res., 32, 217225 (1974).

10) Y. Sanbonsuga: Studies of the growth of fored Laminaria., Bull. Hokkaido Reg. Fish. Res, Lab., 49, 1-75 (1984).

11) A. Fukushi: Seasonal variations of components in different parts of cultivated Japanese Kelp (Laminaria japonica). Sci.
Rept. Hokkaido Fish. Exp. Stat., 31, 55-61 (1988) (in Japanese).

12) M. Sasaki, T. Funaoka, and T. Fukumi: Study on Laminaria japonica of forced cultivation growing on Minami-kayabe. Ann. Sci. Rept. Hokkaido-Hakodate Fish. Exp. Sta., 1980, pp. 105-125 (in Japanese).

13) M. Yokoyama, Y. Sanbonsuga, and S. Torii: Seasonal variations of components of forced cultivated Laminaria during growth process. Bull. Hokkaido Reg. Fish. Res. Lab., 45, 43-50 (1980) (in Japanese)

14) S. Kawashima: Kombu cultivation in Japan for human foodstuff. Sorui, 32, 379-394 (1984) (in Japanese).

Nippon Sulsan Gakkaishi : Formerly Bull. Japan. Soc. Sci. Fish. 